\title{
How is Bariatric Surgery Improving the Quality of Life of Obese Patients: A Portuguese Cross-Sectional Study
}

\section{O Impacto da Cirurgia Bariátrica na Qualidade de Vida dos Indivíduos Obesos: Um Estudo Português}

José Nuno SILVA ${ }^{1}$, Henrique VASCONCELOS ${ }^{1}$, Margarida FIGUEIREDO-BRAGA², Silvestre CARNEIRO ${ }^{1,3}$ Acta Med Port 2018 Jul-Aug;31(7-8):391-398 - https://doi.org/10.20344/amp.9133

\begin{abstract}
Introduction: Obesity is often accompanied by psychological distress and both can reduce patients' quality of life. Bariatric surgery is proven to be a good method to reduce weight and to alleviate comorbidities, leading ultimately to an improvement in quality of life.

Material and Methods: The authors studied 80 patients enrolled in the Multidisciplinary Bariatric Unit of a central hospital in Porto, Portugal. Patients submitted to Roux-en-Y gastric bypass and sleeve procedures were compared. Laboratory parameters were collected from patients' files. Quality of life and psychological state - depression and anxiety, were evaluated using the Portuguese versions of the Medical Outcomes Study SF-36 and the hospital anxiety and depression scale, respectively, within one to two years of the surgery. Results: A total of 51 patients were operated and completed a quality of life evaluation, while 21 patients were in a pre-operatory group (control). Patients subjected to bariatric surgery had higher scores of SF-36 and lower scores in both hospital anxiety and depression scale (anxiety and depression) subscales $(p<0.001)$; SF-36 presented a Pearson correlation coefficient of $0,475(p=0.004)$ with hemoglobin A1c. Sleeve had better results in the hospital anxiety and depression scale-depression subscale $(p=0.073)$.

Discussion: In this population, bariatric surgery led to better results, regarding both metabolic and psychological evaluations. No significant differences were found between gastric bypass and sleeve. However, further analyses must be performed.

Conclusion: This study supports the theory that bariatric surgery contributes to the improvement of obese patients' quality of life and psychological state.
\end{abstract}

Keywords: Anxiety; Bariatric Surgery; Depression; Obesity/surgery; Obesity, Morbid/surgery; Quality of Life

\section{RESUMO}

Introdução: A obesidade é frequentemente acompanhada por perturbações psicológicas, e ambos podem reduzir a qualidade de vida dos doentes. Está provado que a cirurgia bariátrica é um bom método de redução de peso e para aliviar comorbilidades, conduzindo em última instância a uma melhoria da qualidade de vida.

Material e Métodos: Os autores estudaram 80 doentes seguidos em consulta do Centro Multidisciplinar de Tratamento da Obesidade. Os grupos de bypass gástrico em Y-de-Roux e sleeve gástricos foram comparados. Os parâmetros analíticos foram recolhidos dos processos dos doentes. A qualidade de vida e perturbações psicológicas (depressão e ansiedade) foram avaliadas um a dois anos após a cirurgia usando as versões portuguesa do Medical Outcomes Study SF-36 e da escala de depressão e ansiedade hospitalar. Resultados: Um total de 51 doentes foi operado, tendo completado uma avaliação de qualidade de vida, enquanto 21 estavam num grupo pré-operatório (controlo). Doentes submetidos a cirurgia bariátrica tiveram resultados mais elevados no SF-36 e valores menores em ambas as subescalas (ansiedade e depressão) da escala de depressão e ansiedade hospitalar $(p<0,001)$. O SF-36 apresentou um coeficiente de correlação de Pearson de 0,475 ( $p=0,004)$ com a hemoglobina A1c. O sleeve teve melhores resultados na subescala escala de depressão e ansiedade hospitalar-depressão $(p=0,073)$.

Discussão: Nesta população, a cirurgia bariátrica conduziu a melhores resultados nas avaliações metabólica e psicológica, não tendo sido encontradas diferenças significativas entre bypass e sleeve. Contudo, uma análise posterior deverá ser realizada.

Conclusão: Este estudo corrobora a teoria de que a cirurgia bariátrica contribui para a melhoria da qualidade de vida e do estado psicológico dos doentes obesos.

Palavras-chave: Ansiedade; Cirurgia Bariátrica; Depressão; Obesidade Obesidade/cirurgia; Obesidade Mórbida/cirurgia; Qualidade de Vida

\section{INTRODUCTION}

Obesity has a very strong and negative worldwide impact on public health. Along with type 2 diabetes mellitus (DM II), it is one of the most prevalent chronic diseases in the western world. ${ }^{1-5}$ Obesity is considered, besides DM II, to be one of the main risk factors of metabolic syndrome $e^{6,7}$ and other metabolic syndrome-related comorbidities, such as high blood pressure and dyslipidemia. These risk factors are considered very dangerous at cardiovascular level, leading to an increased risk of micro and macrovascular events $^{8-10}$ and ultimately to a decrease in quality of life and

life expectancy. ${ }^{11}$

Several studies have shown impairment in obese patients' overall health, and even shown a correlation between body mass index and a decrease in physical, social and professional functioning, thus establishing an association between obesity and the reduction of quality of life..$^{12,13}$ Besides diminishing physical capacity, obesity has a negative and important impact in patients' mental health. ${ }^{14}$ Depression has been found to be a common comorbidity in obese patients, particularly in those enrolled in bariatric

1. Faculty of Medicine. University of Porto. Porto. Portugal.

2. Department of Clinical Neurosciences and Mental Health. Faculty of Medicine. University of Porto. Porto. Portugal.

3. Department of General Surgery. Centro Hospitalar de São João. Porto. Portugal.

$\triangle$ Autor correspondente: José Nuno Silva. josenunobritodasilva@gmail.com

Recebido: 28 de abril de 2017 - Aceite: 15 de maio de 2018| Copyright $\odot$ Ordem dos Médicos 2018 
procedures. In fact, depression and anxiety have been reported in high rates in groups of patients with obesity. ${ }^{15,16}$

Weight loss in obese patients has a great beneficial potential in physical and psychological health, and constitutes a preventive strategy for related metabolic risks. ${ }^{17-19}$ Bariatric surgery is one of the most effective therapeutic tools to achieve weight reduction..$^{20,21}$ It has already proven not just to be safe and efficient ${ }^{22}$ but also to be an effective method of reducing the negative burden of metabolic comorbidities, such as hyperlipidemia, hyperglycemia or hypertension, which are more prevalent in the obese population. ${ }^{23-25}$ Several studies suggest a positive impact of bariatric procedures in the improvement of patients' lipid profiles (including high- and low-density lipoproteins), glucose metabolism and homeostasis. ${ }^{26-28}$ Some authors have even demonstrated recovery or actual resolution of type 2 diabetes after bariatric surgery. ${ }^{29-31}$ The impact of the improvement of the parameters of the metabolic syndrome on the patients' quality of life appears to be mediated by an enhanced daily and occupational activity. ${ }^{32}$

Bariatric surgery alone appears to be a good method for enhancing patients' quality of life. It has a positive effect on patients' psychological state,,$^{33,34}$ showing the capability to improve physical, mental and social functions in obese patients that undergo the bariatric procedure. ${ }^{35}$

This 'surgical benefit', however, may vary according to the chosen surgical procedure. When studying metabolic parameters, some reports have shown better results at the 1-year stage (regarding body mass index and levels of cholesterol, glycated hemoglobin and glucose) with gastric Y-en-Roux bypass comparing to gastric sleeve, ${ }^{36}$ while others fail to have found significant differences between these two procedures. ${ }^{22}$ But in the long run the vast majority of the studies show a clear advantage in favor of gastric Y-en-Roux bypass. When analyzing psychosocial parameters and the 'surgical efficacy' at the 1-year stage, some doubts have also been raised. Studies using the SF36 questions have shown that either procedure improves quality of life without significant differences except in the dimensions that concern emotional changes, where there is a tendency for sleeve gastrectomy to perform better. ${ }^{37,38}$

We aimed to evaluate to what extent does bariatric surgery contributes to the improvement of the metabolic parameters and quality of life in obese patients subjected to two different bariatric procedures. Secondarily, we intend to uncover differences between the two surgical procedures regarding the referred outcomes and to clarify the relationship between metabolic recovery and health related quality of life.

\section{MATERIAL AND METHODS}

\section{Psychosocial evaluation}

The psychosocial evaluation included the Portuguese versions of the Medical Outcomes Study 36 - Item Short Form Health Survey (SF-36) and the hospital anxiety and depression scale (HADS).

\section{Instruments}

SF-36 is a generic health measurement instrument that contains 36 items covering eight different health dimensions, being one of the instruments with greater potential in clinical results evaluation. ${ }^{39}$ It aims to measure health concepts that represent basic human values relevant to their well-being and ability to function properly. ${ }^{40}$ The eight health concepts studied in the SF-36 can be divided into two groups: physical health (physical functioning; body pain; limitations in usual role activities due to physical health and general health perception) and mental health (emotional role functioning; social role functioning; mental health and vitality). The scores for each health concept range from 0 to 100 , with low scores representing poorer quality of life and a score of 100 representing the best quality of life possible. ${ }^{41} \mathrm{We}$ used the Portuguese version of the questionnaire, adapted by Ferreira. ${ }^{42}$

The $\mathrm{HADS}^{43}$ version that was used was translated and adapted $^{44}$ to the Portuguese language. It is a reliable and valid method to assess both anxiety and depression, useful in a community setting ${ }^{45-47}$ for initial diagnosis and tracking of progression or resolution of psychological symptoms. ${ }^{48}$ It consists of a self-rating scale that can provide clinically meaningful results as a screening tool for psychological disorders. It comprises fourteen questions, half for anxiety (HADS-A subscale) and the other half for depression (HADS-D subscale), with these two groups being scored independently. This scale has four different cut-offs: normal $0-7$, mild $8-10$, moderate $11-14$, and severe $15-21 .{ }^{43}$ A score of 8 or more for anxiety has a specificity of 0.78 and a sensitivity of 0.9 for the detection of a psychiatric disorder and for depression a specificity of 0.79 and a sensitivity of 0.83 are reported. ${ }^{45}$

\section{Clinical and surgical evaluation}

Clinical and surgical evaluation such as the type of bariatric procedure used, the use of 'metabolic medication' (anti-hypertensive drugs, anti-dyslipidemic drugs and oral antidiabetics) and the evolution of the body mass index (BMI) parameter were evaluated.

\section{Laboratory data}

Analytical parameters from the MBU consultations were collected from the participant's clinical file; in the surgical groups, the information regarding the 1-year post-operatory consultation. The parameters included were glycated hemoglobin (hemoglobin A1c), glucose, total cholesterol, HDL-cholesterol, LDH-cholesterol and triglycerides. The Atherogenic Index of Plasma (AIP) ${ }^{49}$ was calculated using $\mathrm{HDL}$-cholesterol and triglycerides, in order to evaluate the positive and negative effect of these lipids.

\section{Statistical Analysis}

Statistical analysis was performed using Statistical Package for the Social Sciences Software (SPSS 24.0 ${ }^{\circledR}$ ). Mean comparisons were performed using parametric (independent-samples $t$-test and Levene) tests. The 
normality of the analyzed parameters distribution was verified using Shapiro-Wilk test. Correlation was assessed through Pearson correlation coefficient. A p-value less than 0.05 was considered as statistically significant.

\section{Population}

The study was conducted at the Multidisciplinary Bariatric Unit (MBU), an outpatient unit in Centro Hospitalar São João (CHSJ). It follows a cross sectional observational design. A total of eighty patients were enrolled to participate in the study.

The main group consisted of patients that were already enrolled in the Bariatric Surgery Unit outpatient department of CHSJ. The Inclusion criteria was a visit between October 2016 and March 2017. Participants were divided in two subgroups. The first subgroup (group 1) consisted of patients with obesity that had been subjected to Bariatric Surgery in the Bariatric Surgery Unit of CHSJ and attended at least one pre-operative and one post-operative MBU visit. The exclusion criteria were to have been subjected to any bariatric procedure other than gastric Y-en-Roux bypass or gastric sleeve and not having at least one pre-operatory and one post-operatory complete evaluation.

The second subgroup (group 2) consisted of obese patients that were already enrolled in MBU pre-operatory consultation and were awaiting surgery.

An independent group of patients specifically submitted to metabolic surgery was also considered in this study in order to boost statistical analysis. It consisted of eight patients that were operated in 2014 and 2015 by bariatric surgery for metabolic indications.

All patients signed an informed consent form, after receiving oral and written information of the study protocol and procedures. The study was approved by the Ethical Committee 'Comissão de Ética para a Saúde do Centro Hospitalar de São João'. The confidentiality and privacy of the data were guaranteed according to the Declaration of

Table 1 - Demographic and surgical characterization of participants

\begin{tabular}{|c|c|c|}
\hline \multirow[t]{2}{*}{ Gender } & Male & $17(21.3)^{\mathrm{a}}$ \\
\hline & Female & $63(78.7)^{\mathrm{a}}$ \\
\hline Age (years) & & $45.68(10.83)^{\mathrm{b}}$ \\
\hline Age at surgery (years) & & $44.73(11.47)^{b}$ \\
\hline \multirow[t]{3}{*}{ Type of surgery - n (\%) } & Pre-operatory group & $21(26.3)$ \\
\hline & Bypass & $43(53.7)$ \\
\hline & Sleeve & $16(20.0)$ \\
\hline Groups of patients & $\begin{array}{l}\text { BMI }\left(\mathbf{k g} / \mathrm{m}^{2}\right) \\
\text { Before surgery }\end{array}$ & \\
\hline $\begin{array}{l}\text { Bypass } \\
(n=43)\end{array}$ & $41.41(5.29)^{\mathrm{c}}$ & \\
\hline $\begin{array}{l}\text { Sleeve } \\
(n=16)\end{array}$ & $43.73(5.32)^{c}$ & \\
\hline $\begin{array}{l}\text { Pre-operative } \\
(\mathrm{n}=21)\end{array}$ & $42.71(5.29)^{\mathrm{c}}$ & \\
\hline
\end{tabular}

Helsinki.

\section{Procedures}

The patients included in group 1 answered the Medical Outcomes Study 36 - Item Short - Form Health Survey (SF36) and the hospital anxiety and depression scale (HADS) during their postoperative visits, which took place in the timespan of one to two and a half years. Each patient's clinical file was consulted in order to retrieve relevant surgical, clinical and laboratory data.

Patients in group 2 answered the evaluation questionnaires (SF-36 and HADS) during their pre-operative visits.

In the independent group of non-obese patients subjected to metabolic surgery, the same relevant data mentioned in the first subgroup analysis was extracted from their clinical files.

\section{RESULTS}

\section{Sociodemographic and surgical characterization}

From a total population of 80 patients, 59 had been subjected to a bariatric procedure and 21 were preoperatory patients. A sub population of 51 patients $(64 \%)$ completed the quality of life evaluation.

Participants had a mean age of 45.6 (SD 10.8) years and the majority were females $(79 \%)$. From the total population, 43 patients had been subjected to gastric bypass and 16 to gastric sleeve. The mean body mass index (BMI) of the bypass group was $41.4 \mathrm{~kg} / \mathrm{m}^{2}$ (SD 5.8) and the mean BMI of the sleeve group was $43.7 \mathrm{~kg} / \mathrm{m}^{2}$ (SD 5.3). The mean BMI of the pre-operatory group was $42.7 \mathrm{~kg} / \mathrm{m}^{2}$ (SD 5.3).

Table 1 summarizes the sociodemographic, clinical and surgical characteristics of the evaluated patients.

\section{Medication use before and after surgery}

Some differences were found when comparing the use of medication (anti-hypertensive drugs, anti-dyslipidemic drugs and antidiabetics treatment) before and after surgery. Forty-four percent (44\%) of the patients who were subjected to surgical procedures did not take regular medication; from the remainder $56 \%$ of the patients, $39 \%$ reported to have reduced or stopped their usual medication.

\section{Metabolic parameters}

Both surgical procedures led to an improvement in the metabolic parameters. The mean reductions were 14.3 $\mathrm{mg} / \mathrm{dL}$ (SD: 31.4 ) for total cholesterol, $37.1 \mathrm{mg} / \mathrm{dL}$ (SD: 54.8) for triglycerides, 0.2 (SD: 0.2) for AIP, 0.8\% (SD: 1.2) for Hemoglobin A1c and $12.5 \mathrm{~kg} / \mathrm{m}^{2}$ (SD: 4.5) for BMI. In the sleeve group, pre and post-operatory values were $184.7 \mathrm{mg} / \mathrm{dL}$ (SD: 25.0) and $183.5 \mathrm{mg} / \mathrm{dL}$ (SD: 46.9) for total cholesterol, $124.3 \mathrm{mg} / \mathrm{dL}$ (SD: 57.3 ) and $75.4 \mathrm{mg} / \mathrm{dL}$ (SD: 35.1) for triglycerides, 0.424 (SD: 0.252 ) and 0.066 (SD: 0.155$)$ for AIP, $5.8 \%$ (SD: 1.3) and 5.2\% (SD: 0.5) for hemoglobin A1c, $43.7 \mathrm{~kg} / \mathrm{m}^{2}$ (SD: 5.3 ) and $30.5 \mathrm{~kg} / \mathrm{m}^{2}$ (SD: 5.3) for BMI, respectively. In the bypass group, pre and post-operatory values were $188.6 \mathrm{mg} / \mathrm{dL}$ (SD: 33.2 ) 


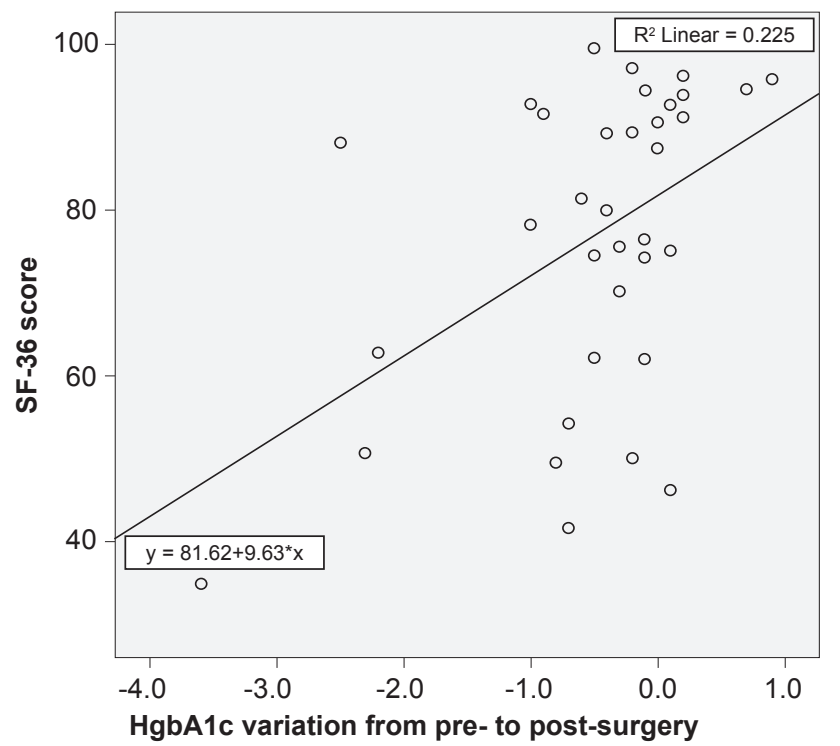

Figure 1 - Correlation between hemoglobin $\mathrm{A} 1 \mathrm{c}$ and the percentage of weight reduction (Pearson correlation coefficient of -0.422)

and $167.7 \mathrm{mg} / \mathrm{dL}$ (SD: 28.0 ) for total cholesterol, $126.3 \mathrm{mg} /$ dL (SD: 61.2 ) and $91.2 \mathrm{mg} / \mathrm{dL}$ (SD: 36.7) for triglycerides, 0.376 (SD: 0.193 ) and 0.186 (SD: 0.185 ) for AIP, $6.4 \%$ (SD: 1.5 ) and $5.6 \%$ (SD: 0.8) for hemoglobin A1c, $41.4 \mathrm{~kg} / \mathrm{m}^{2}$ (SD: 5.8 ) and $29.1 \mathrm{~kg} / \mathrm{m}^{2}$ (SD: 3.8) for BMI, respectively.

A trend was found in patients subjected to bypass to lower total-cholesterol. Sleeve procedure seems to have slightly more impact in the reduction of triglycerides and BMI. However, no statistically significant differences were found in the above-mentioned parameters between the two groups.

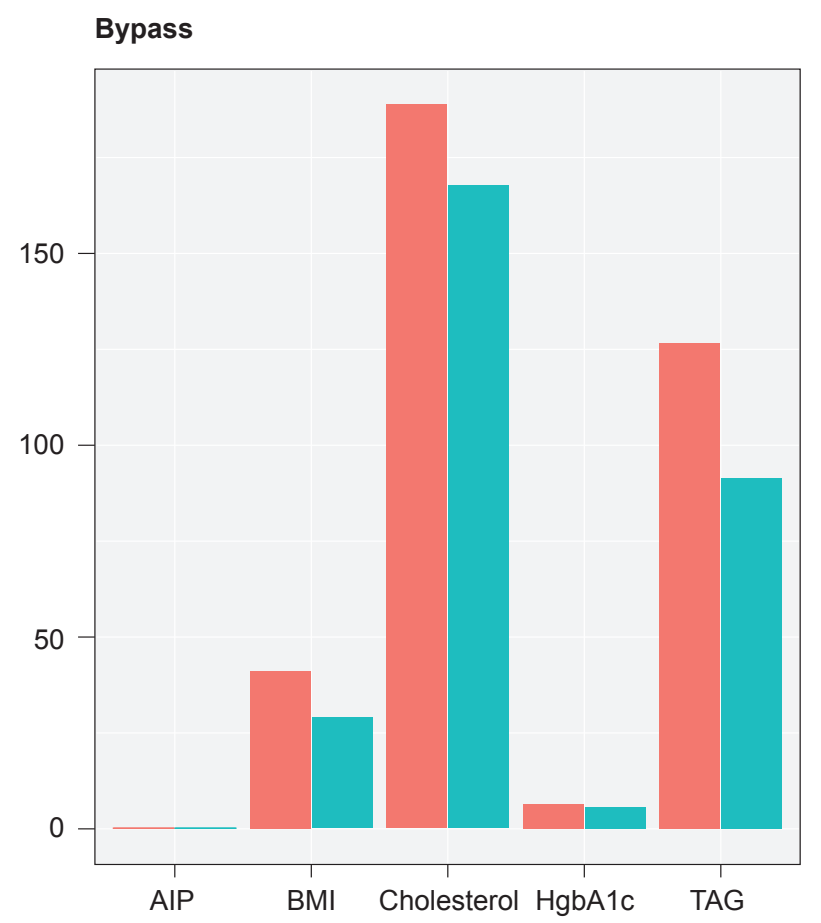

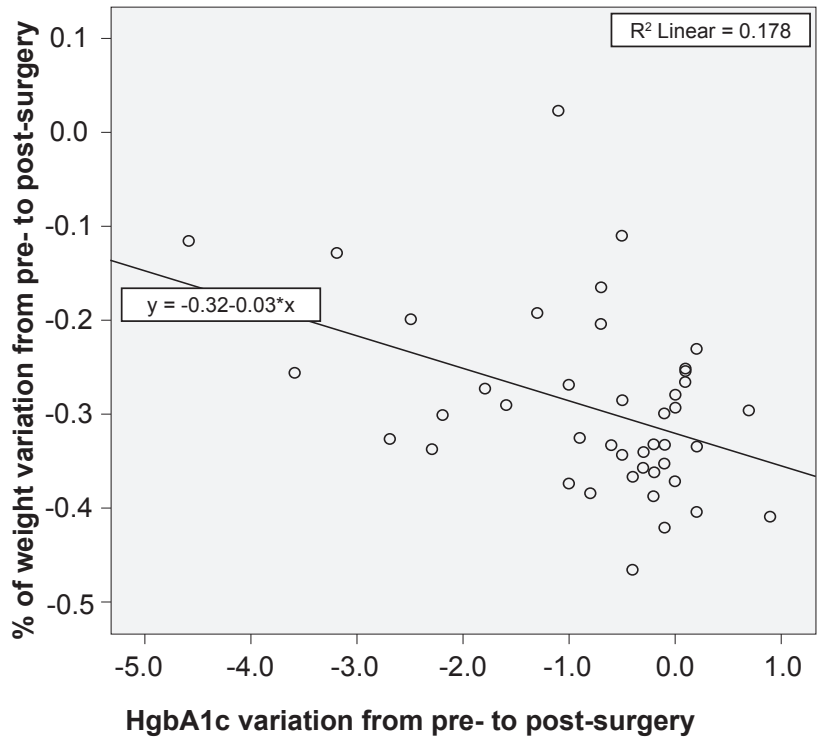

Figure 2 - Descriptive error bars showing the variation in metabolic parameters in both gastric bypass and gastric sleeve groups

The BMI after surgery was lower in both groups, with a $28.4 \%$ reduction in weight in the bypass group and $31.0 \%$ in the sleeve group. In the post-operative period, BMI of the bypass group was $25.7 \mathrm{~kg} / \mathrm{m}^{2}$ (SD 12.3) and the mean BMI of the sleeve group was $29.3 \mathrm{~kg} / \mathrm{m}^{2}$ (SD: 9.5). A negative correlation ( $r=-0.422 ; p=0.005)$ was found between hemoglobin $\mathrm{A} 1 \mathrm{c}$ and the percentage of weight reduction (Fig. 1).

Fig. 2 and Fig. 3 show the comparison between bypass and sleeve regarding metabolic parameters.

\section{Sleeve}

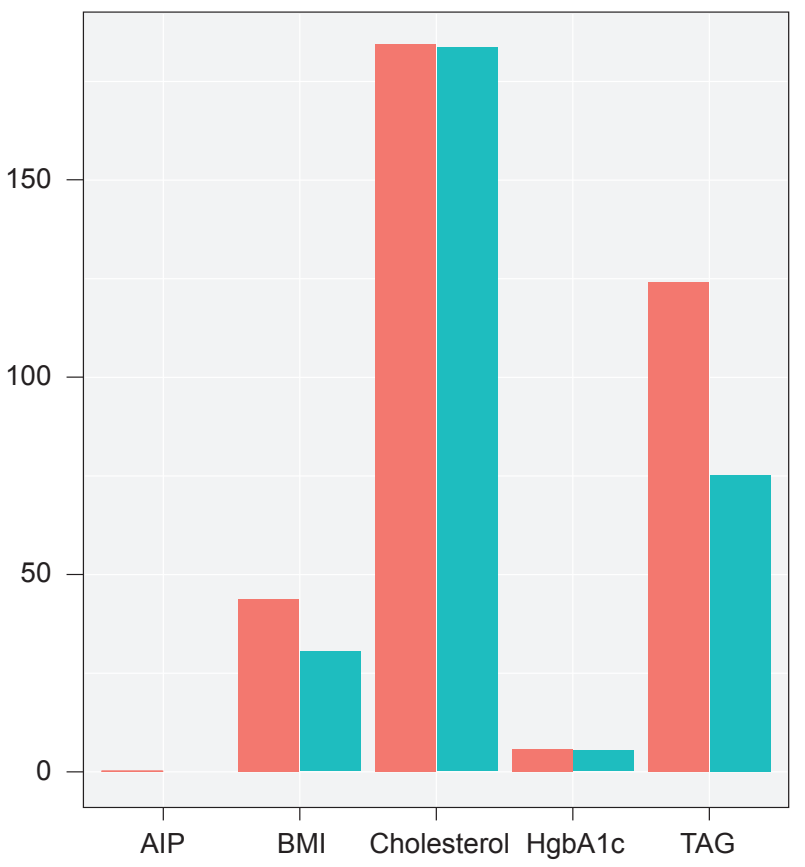

1. Pre

Figure 3 - Descriptive bars showing the pre and post-operatory metabolic values in both the gastric bypass and gastric sleeve groups 
Quality of life (SF-36), anxiety and depression (HADS) evaluation

The approximate time mediating between the surgical procedure and the collection of psychosocial evaluation was of 89 weeks (SD 30) for the sleeve group and of 103 weeks (SD 34) for the bypass group.

In patients subjected to surgery, the SF-36 results showed a median of 84 points in the physical health domain and 79 points for the mental health domain. In the preoperative group, results had a median of 38 points in the physical health domain and 43 points for the mental health domain. The differences between pre-operatory group and surgical group regarding both components of SF-36 were significant $(p<0.001)$, with a mean difference of 40.6 points and 31.0 points for the physical and mental component, respectively. No significant differences between bypass and sleeve were found in the physical or mental health domain of SF-36 ( $p=0.278$ and $p=0.533$, respectively). Table 2 summarizes the quality of life in the bypass and sleeve groups assessed by the SF-36 Health Survey.

Anxiety symptoms (mild, moderate and severe) were experienced by $66.7 \%$ of pre-operatory patients, $20.6 \%$ of bypass patients and $7.1 \%$ of sleeve patients. Depressive symptoms were experienced by $61.9 \%, 15.2 \%$ and $0 \%$ of patients, respectively. Table 3 presents the distribution, sorted by bariatric procedure, of anxiety and depression HADS scores. We found no significant differences between bypass and sleeve both in the Anxiety scale $(p=0.828)$ as in the Depression scale $(p=0.073)$. However, a tendency was detected for lower HADS-D scores in the patients subjected to sleeve procedure $(p=0.073$ is marginally nonsignificant).

When comparing SF-36, HADS-A and HADS-D results between pre-operative and post-operative groups, significant differences were found in all three ( $p$ values $<0.001$ ), with higher scores in SF-36 (mean difference of 35.4 points) and lower scores in HADS subscales (mean differences of 5.9 and 5.5 in depression and anxiety, respectively) in patients subjected to both bariatric procedures.

\section{Correlations between metabolic evaluation and quality of life, anxiety and depressive symptoms}

Correlations between hemoglobin A1c, AIP and BMI and SF-36 and HADS were calculated using Pearson correlation coefficients.

A significant positive correlation $(r=0.475 ; p=0.004)$ was found between hemoglobin A1c and SF-36 (Fig. 4). No correlations were found between the other metabolic parameters and SF-36 and HADS scores.

\section{DISCUSSION}

Both mental and physical components of the SF-36 were higher in patients subjected to bariatric surgery at the end of the 1st year than in the pre-operative group.

Table 2 - Quality of life evaluation (SF-36 Health Survey)

\begin{tabular}{|c|c|c|c|c|c|}
\hline SF-36 & & Bypass (B) & Sleeve $(S)$ & Pre-operative (PO) & $p$ value \\
\hline \multirow{5}{*}{ 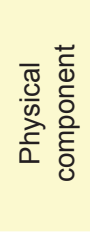 } & PF - physical function ${ }^{a}$ & $100(75 ; 100)$ & $98(50 ; 100)$ & $55(15 ; 90)$ & $\mathbf{B}$ vs $\mathbf{S}: 0.859^{\mathrm{b}}$ \\
\hline & PP - physical performance ${ }^{a}$ & $100(0 ; 100)$ & $75(0 ; 100)$ & $0(0 ; 25)$ & B vs S: $\underline{0.136}^{b}$ \\
\hline & BP - bodily pain ${ }^{a}$ & $100(32 ; 100)$ & $100(41 ; 100)$ & $41(12 ; 100)$ & B vs S: $\underline{0.423}^{b}$ \\
\hline & $\mathrm{GH}$ - global health ${ }^{\mathrm{a}}$ & $82(50 ; 100)$ & $77(30 ; 90)$ & $40(0 ; 92)$ & B vs S: ${\underline{0.441^{b}}}^{b}$ \\
\hline & Physical health domain ${ }^{a}$ & $86(41 ; 100)$ & $89(37 ; 98)$ & $38(7 ; 61)$ & $\begin{array}{c}\text { B vs S: }{\underline{0.278^{b}}}_{(B+S) \text { vs } \mathrm{PO}:<0.001^{\mathrm{c}}}\end{array}$ \\
\hline \multirow{5}{*}{ 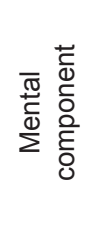 } & VT - vitality ${ }^{\mathrm{a}}$ & $80(45 ; 100)$ & $80(50 ; 100)$ & $40(0 ; 75)$ & B vs S: $\underline{0.360}^{\mathrm{b}}$ \\
\hline & SF - social function ${ }^{a}$ & $100(63 ; 100)$ & $88(25 ; 100)$ & $63(13 ; 100)$ & B vs S: $\underline{0.484}^{b}$ \\
\hline & EM - emotional performance ${ }^{a}$ & $100(0 ; 100)$ & $50(0 ; 100)$ & $0(0 ; 100)$ & B vs S: $\underline{0.244}^{b}$ \\
\hline & $\mathrm{MH}$ - mental health ${ }^{\mathrm{a}}$ & $76(44 ; 100)$ & $72(28 ; 100)$ & $50(12 ; 100)$ & B vs S: ${\underline{0.613^{b}}}^{b}$ \\
\hline & Mental health domain ${ }^{a}$ & $83(38 ; 100)$ & $79(32 ; 97)$ & $43(11 ; 91)$ & $\begin{array}{c}\text { B vs S: }{\underline{0.533^{\mathrm{b}}}}^{(\mathrm{B}+\mathrm{S}) \text { vs } \mathrm{PO}:<0.001^{\mathrm{c}}}\end{array}$ \\
\hline
\end{tabular}

a: median (min; max); ${ }^{\text {: }}$ independent samples $t$-test comparing bypass and sleeve groups; ${ }^{c}:$ independent samples t-test comparing surgical and pre-operative groups

Table 3 - Presence of anxiety and depression symptoms screening by HADS scores in bypass and sleeve groups

\begin{tabular}{|c|c|c|c|c|c|}
\hline & & Bypass (B) & Sleeve (S) & Pre-operatory (PO) & $p$ value \\
\hline \multirow{5}{*}{ 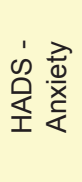 } & Median & 4 & 4 & 11 & \multirow{5}{*}{$\begin{array}{c}\text { B vs S: } \underline{0.828}^{\mathrm{a}} \\
(\mathrm{B}+\mathrm{S}) \text { vs } \mathrm{PO}:<0.001\end{array}$} \\
\hline & Normal $(0-7)$ & $79.4 \%$ & $92.9 \%$ & $33.3 \%$ & \\
\hline & Mild $(8-10)$ & $14.8 \%$ & $0.0 \%$ & $4.8 \%$ & \\
\hline & Moderate $(11-14)$ & $2.9 \%$ & $0.0 \%$ & $47.6 \%$ & \\
\hline & Severe $(15-21)$ & $2.9 \%$ & $7.1 \%$ & $14.3 \%$ & \\
\hline \multirow{5}{*}{ 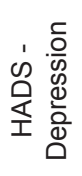 } & Median & 2 & 1 & 10 & \multirow{5}{*}{$\begin{array}{c}\text { B vs S: }{\underline{0.073^{\mathrm{a}}}}^{(\mathrm{B}+\mathrm{S}) \text { vs } \mathrm{PO}:<0.001}\end{array}$} \\
\hline & Normal $(0-7)$ & $84.8 \%$ & $100 \%$ & $38.1 \%$ & \\
\hline & Mild $(8-10)$ & $12.2 \%$ & $0.0 \%$ & $33.3 \%$ & \\
\hline & Moderate $(11-14)$ & $3.0 \%$ & $0.0 \%$ & $19.1 \%$ & \\
\hline & Severe $(15-21)$ & $0.0 \%$ & $0.0 \%$ & $9.5 \%$ & \\
\hline
\end{tabular}

${ }^{a}$ : independent samples t-test comparing bypass and sleeve groups; ${ }^{b}$ : independent samples $t$-test comparing surgical and pre-operatory groups 


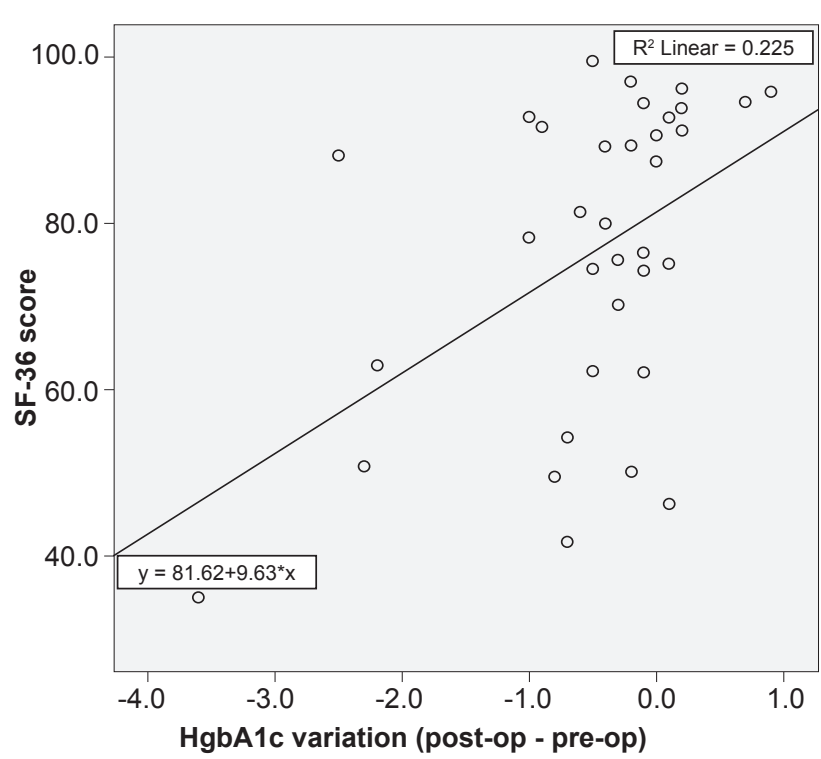

Figure 4 - Correlations between hemoglobin A1c and the SF-36 Health Survey (Pearson correlation coefficient of 0.475)

In addition, psychological distress evaluation indicated a better psychological state in patients who were subjected to surgery. This shows that bariatric procedures can improve both obese patients' mood and quality of life, as reported by Karlsson et al, ${ }^{50}$ Reynolds et al, ${ }^{51}$ and Dixon et al. ${ }^{15}$ We also found that in this population, hemoglobin $\mathrm{A} 1 \mathrm{c}$ reduction was associated with an increase in the global SF-36 score and less anxiety symptoms.

In our sample, patients subjected to bariatric surgery showed a reduction both in BMI and in metabolic parameters, with no significant differences between the two groups (bypass and sleeve) at 1-year stage. This finding is in line with Bonner et $a^{22}$ who observed similar results of both procedures in the reduction of hemoglobin $\mathrm{A} 1 \mathrm{C}$ and LDL-cholesterol. However, other authors have reported better results in the improvement of hemoglobin A1c, lipid profile and BMI when gastric bypass was used, especially in studies with larger follow-up periods..$^{28,36}$

Regarding the evaluation of quality of life, patients subjected to bypass and sleeve techniques presented similar results in each dimension, global assessment and in mental and physical dimensions of quality of life..$^{37}$ Previous studies also fail to uncover differences between patients subjected to both surgical interventions concerning quality of life. Therefore, and in case our findings are corroborated by studies with larger follow-up periods, the lack of significant differences in the metabolic and quality of life outcomes between the bypass and sleeve groups forces us to ask a pertinent question: "when both techniques are available, are there any differences in the patients' outcome that should make us choose one instead of the other?".

Anxiety and depression are frequently associated with obesity, and "both act synergistically on physical and mental quality of life". ${ }^{2}$ Moreover detection and treatment of these psychiatric disorders and weight loss may be important factors to enhance quality of life. In the present study, no relevant differences in the occurrence of anxiety and depressive symptoms were detected between patients subjected to sleeve or bypass procedures. However, results suggest that sleeve gastrectomy shows a tendency to have a greater positive impact in depression, with a higher capability to improve this psychological impairment.

A limitation of the present study is its cross-sectional design, preventing comparisons in the same patients before and after surgery. Prospective studies that follow the same patients before and after the procedure, such as described by Reynolds et al, ${ }^{51}$ are required to overcome this limitation. Furthermore, a larger follow-up period would be necessary to confirm the impact of surgery in the regular medication of patients and to have a broader perspective of the surgical influence on metabolic parameters and quality of life. As stated by Karlsson et al, reports on bariatric surgery and quality of life changes up to 1 year should be analyzed cautiously. ${ }^{53}$ Another limitation is the lack of information on pre-existing comorbidities that could also interfere with the patients' quality of life, namely the presence of psychiatric disorders. Another limitation is about the comparative morbidity between sleeve and bypass, as a strong factor in quality of life.

\section{CONCLUSION}

In conclusion, our findings support the thesis that bariatric surgery helps improve obese patient's quality of life and reduce psychological distress. Two recent reviews have reinforced the impact of bariatric surgery on physical QOL, but the impact on psychosocial variables and mental health remains apparently variable over time. ${ }^{54,55}$

From the biological outcomes of the surgery, hemoglobin A1c is the metabolic parameter that better signals changes in the quality of life measures in the present study.

It has also been shown that the outcomes of bariatric surgery have a tendency to be related to the presence of depression. Pre-operatory screening and treatment of depression and anxiety could add to the efficacy and amplify weight loss in patients after surgery ${ }^{56}$ enhancing quality of life in a more continuous way.

To elucidate this aspect, as mentioned by other authors, we believe other studies are required. Despite all the advantages achieved by the use of bariatric surgery in obese patients, it is imperative to combine broader lifestyle measures in order to accomplish positive long-term goals, as suggested by Glatt et al. ${ }^{23}$ Considering these disparities, we consider to be highly recommended to carry out a larger study aiming to clarify this issue.

\section{PROTECTION OF HUMANS AND ANIMALS AND DATA CONFIDENTIALITY}

The authors declare that the study was approved by the Ethical Committee 'Comissão de Ética para a Saúde do Centro Hospitalar de São João'. The confidentiality and privacy of the data were guaranteed according to the Declaration of Helsinki. 


\section{CONFLICTS OF INTEREST}

All authors report no conflict of interest.

\section{REFERENCES}

1. Zimmet P, Alberti KG, Shaw J. Global and societal implications of the diabetes epidemic. Nature. 2001;414:782-7.

2. Alberti KG, Zimmet P. Global burden of disease-where does diabetes mellitus fit in? Nat Rev Endocrinol. 2013;9:258-60.

3. Chaker L, Falla A, van der Lee SJ, Muka T, Imo D, Jaspers L, et al. The global impact of non-communicable diseases on macro-economic productivity: a systematic review. Eur J Epidemiol. 2015;30:357-95.

4. International Diabetes Federation. IFD Diabetes Atlas. Brussels: IFD; 2016.

5. Caballero B. The global epidemic of obesity: an overview. Epidemiol Rev. 2007;29:1-5.

6. Cameron AJ, Boyko EJ, Sicree RA, Zimmet PZ, Soderberg S, Alberti $K G$, et al. Central obesity as a precursor to the metabolic syndrome in the AusDiab study and Mauritius. Obesity. 2008;16:2707-16.

7. Eckel RH, Alberti K, Grundy SM, Zimmet PZ. The metabolic syndrome. Lancet. 2010;375:181-3.

8. Williams S, Cunningham E, Pories WJ. Surgical treatment of metabolic syndrome. Med Princ Pract. 2012;21:301-9.

9. Lee WJ, Huang MT, Wang W, Lin CM, Chen TC, Lai IR. Effects of obesity surgery on the metabolic syndrome. Arch Surg. 2004;139:1088-92.

10. Alberti KG, Eckel RH, Grundy SM, Zimmet PZ, Cleeman JI, Donato KA, et al. Harmonizing the metabolic syndrome: a joint interim statement of the International Diabetes Federation Task Force on Epidemiology and Prevention; National Heart, Lung, and Blood Institute; American Heart Association; World Heart Federation; International Atherosclerosis Society; and International Association for the Study of Obesity. Circulation. 2009;120:1640-5.

11. Stamler J, Vaccaro O, Neaton JD, Wentworth D. Diabetes, other risk factors, and 12-yr cardiovascular mortality for men screened in the Multiple Risk Factor Intervention Trial. Diabetes Care. 1993;16:434-44.

12. Cameron AJ, Magliano DJ, Dunstan DW, Zimmet PZ, Hesketh K, Peeters A, et al. A bi-directional relationship between obesity and healthrelated quality of life: evidence from the longitudinal AusDiab study. Int J Obes. 2012;36:295-303.

13. Kortt MA, Dollery B. Association between body mass index and health-related quality of life among an Australian sample. Clin Ther. 2011;33:1466-74.

14. Ul-Haq Z, Mackay DF, Fenwick E, Pell JP. Meta-analysis of the association between body mass index and health-related quality of life among adults, assessed by the SF-36. Obesity. 2013;21:E322-7.

15. Dixon JB, Dixon ME, O'Brien PE. Depression in association with severe obesity: changes with weight loss. Arch Intern Med. 2003;163:2058-65.

16. Kalarchian MA, Marcus MD, Levine MD, Courcoulas AP, Pilkonis PA, Ringham RM, et al. Psychiatric disorders among bariatric surgery candidates: relationship to obesity and functional health status. Am J Psychiatry. 2007;164:328-34.

17. Li G, Zhang P, Wang J, An Y, Gong Q, Gregg EW, et al. Cardiovascular mortality, all-cause mortality, and diabetes incidence after lifestyle intervention for people with impaired glucose tolerance in the Da Qing Diabetes Prevention Study: a 23-year follow-up study. Lancet Diabetes Endocrinol. 2014;2:474-80.

18. Dattilo AM, Kris-Etherton PM. Effects of weight reduction on blood lipids and lipoproteins: a meta-analysis. Am J Clin Nutr. 1992;56:320-8.

19. Webber L, Kilpi F, Marsh T, Rtveladze K, Brown M, McPherson K. High rates of obesity and non-communicable diseases predicted across Latin America. PLoS One. 2012;7:e39589.

20. Christ-Crain M, Stoeckli R, Ernst A, Morgenthaler NG, Bilz S, Korbonits $M$, et al. Effect of gastric bypass and gastric banding on proneurotensin levels in morbidly obese patients. J Clin Endocrinol Metab. 2006;91:35447.

21. Dixon JB, Strauss BJ, Laurie C, O'Brien PE. Changes in body composition with weight loss: obese subjects randomized to surgical and medical programs. Obesity. 2007;15:1187-98.

22. Bonner GL, Nagy AJ, Jupiter DC, Rodriguez JA, Symmonds RE, Jr., Carpenter RO. A comparison of postoperative effects of bariatric surgery on medical markers of morbidity. Am J Surg. 2014;208:897-902.

23. Glatt D, Sorenson T. Metabolic and bariatric surgery for obesity: a review. S D Med. 2011;57-62.

\section{FUNDING SOURCES}

This research received no specific grant from any funding agency in the public, commercial, or not-for-profit sectors.

24. Black JA, White B, Viner RM, Simmons RK. Bariatric surgery for obese children and adolescents: a systematic review and meta-analysis. Obes Rev. 2013;14:634-44.

25. Sjostrom L, Lindroos AK, Peltonen M, Torgerson J, Bouchard C Carlsson B, et al. Lifestyle, diabetes, and cardiovascular risk factors 10 years after bariatric surgery. N Engl J Med. 2004;351:2683-93.

26. Garcia-Marirrodriga I, Amaya-Romero C, Ruiz-Diaz GP, Fernandez S, Ballesta-Lopez C, Pou JM, et al. Evolution of lipid profiles after bariatric surgery. Obes Surg. 2012;22:609-16.

27. Williams DB, Hagedorn JC, Lawson EH, Galanko JA, Safadi BY, Curet $\mathrm{MJ}$, et al. Gastric bypass reduces biochemical cardiac risk factors. Surg Obes Relat Dis. 2007;3:8-13.

28. Rubino F, Schauer PR, Kaplan LM, Cummings DE. Metabolic surgery to treat type 2 diabetes: clinical outcomes and mechanisms of action. Annu Rev Med. 2010;61:393-411.

29. Schauer PR, Kashyap SR, Wolski K, Brethauer SA, Kirwan JP, Pothier $\mathrm{CE}$, et al. Bariatric surgery versus intensive medical therapy in obese patients with diabetes. N Engl J Med. 2012;366:1567-76.

30. Hofso D, Jenssen T, Bollerslev J, Ueland T, Godang K, Stumvoll M, et al. Beta cell function after weight loss: a clinical trial comparing gastric bypass surgery and intensive lifestyle intervention. Eur $\mathrm{J}$ Endocrinol. 2011;164:231-8.

31. Dogan K, Betzel B, Homan J, Aarts EO, Ploeger N, de Boer H, et al. Long-term effects of laparoscopic Roux-en-Y gastric bypass on diabetes mellitus, hypertension and dyslipidaemia in morbidly obese patients. Obes Surg. 2014;24:1835-42.

32. Sharples AJ, Cheruvu CV. Systematic review and meta-analysis of occupational outcomes after bariatric surgery. Obes Surg. 2017;27:77481.

33. Wadden TA, Faulconbridge LF, Jones-Corneille LR, Sarwer DB, Fabricatore AN, Thomas JG, et al. Binge eating disorder and the outcome of bariatric surgery at one year: a prospective, observational study. Obesity. 2011;19:1220-8.

34. Hillstrom KA, Graves JK. A review of depression and quality of life outcomes in adolescents post bariatric surgery. J Child Adolesc Psychiatr Nurs. 2015;28:50-9.

35. Faulconbridge LF, Wadden TA, Thomas JG, Jones-Corneille LR, Sarwer $\mathrm{DB}$, Fabricatore AN. Changes in depression and quality of life in obese individuals with binge eating disorder: bariatric surgery versus lifestyle modification. Surg Obes Relat Dis. 2013;9:790-6.

36. Lee WJ, Chong K, Ser KH, Lee YC, Chen SC, Chen JC, et al. Gastric bypass vs sleeve gastrectomy for type 2 diabetes mellitus: a randomized controlled trial. Arch Surg. 2011;146:143-8.

37. Major P, Matlok M, Pedziwiatr M, Migaczewski M, Budzynski P, Stanek M, et al. Quality of life after bariatric surgery. Obes Surg. 2015;25:170310.

38. Macano CA, Nyasavajjala SM, Brookes A, Lafaurie G, Riera M. Comparing quality of life outcomes between laparoscopic sleeve gastrectomy and laparoscopic Roux-en-Y gastric bypass using the RAND36 questionnaire. Int J Surg. 2017;42:138-42.

39. Alonso J, Prieto L, Anto JM. La versión española del SF-36 Health Survey (Cuestionario de Salud SF-36): un instrumento para la medida de los resultados clínicos. Med Clin. 1995;104:771-6.

40. Ware JE, Jr. Standards for validating health measures: definition and content. J Chronic Dis. 1987;40:473-80.

41. Ware JE, Jr., Sherbourne CD. The MOS 36-item short-form health survey (SF-36). I. Conceptual framework and item selection. Med Care. 1992;30:473-83.

42. Ferreira PL. Development of the Portuguese version of MOS SF-36. Part I. Cultural and linguistic adaptation. Acta Med Port. 2000;13:55-66.

43. Zigmond AS, Snaith RP. The hospital anxiety and depression scale. Acta Psychiatr Scand. 1983:361-70.

44. Pais-Ribeiro J, Silva I, Ferreira T, Martins A, Meneses R, Baltar M. Validation study of a Portuguese version of the Hospital Anxiety and Depression Scale. Psychol Health Med. 2007;12:225-35.

45. Bjelland I, Dahl AA, Haug TT, Neckelmann D. The validity of the hospital anxiety and depression scale. An updated literature review. J Psychosom Res. 2002;52:69-77. 
46. Snaith RP. The hospital anxiety and depression scale. Health Qual Life Outcomes. 2003;1:29.

47. Herrmann C. International experiences with the hospital anxiety and depression scale-a review of validation data and clinical results. J Psychosom Res. 1997;42:17-41.

48. McManus S, Meltzer H, Brugha T, Bebbington P, Jenkins R. Adult psychiatric morbidity in England. Results of household survey. Leeds: NHS; 2007

49. Dobiásová M. Atherogenic Index of Plasma. Clin Chem. 2004;50:11135.

50. Karlsson J, Taft C, Ryden A, Sjostrom L, Sullivan M. Ten-year trends in health-related quality of life after surgical and conventional treatment for severe obesity: the SOS intervention study. Int J Obes. 2007;31:124861.

51. Reynolds CL, Byrne SM, Hamdorf JM. Treatment success: investigating clinically significant change in quality of life following bariatric surgery. Obes Surg. 2017;27:1842-8.
52. Luppino FS, de Wit LM, Bouvy PF, Stijnen T, Cuijpers P, Penninx BW, et al. Overweight, obesity, and depression: a systematic review and metaanalysis of longitudinal studies. Arch Gen Psychiatry. 2010;67:220-9.

53. Karlsson J, Taft C, Sjostrom L, Torgerson JS, Sullivan M. Psychosocial functioning in the obese before and after weight reduction: construct validity and responsiveness of the obesity-related problems scale. Int J Obes Relat Metab Disord. 2003;27:617-30.

54. Mazer LM, Azagury DE, Morton JM. Quality of life after bariatric surgery. Curr Obes Rep. 2017;6:204-10.

55. Jumbe S, Bartlett C, Jumbe SL, Meyrick J. The effectiveness of bariatric surgery on long term psychosocial quality of life - a systematic review. Obes Res Clin Pract. 2016;10:225-42.

56. Nicolau J, Simo R, Sanchis P, Ayala L, Fortuny R, Rivera R, et al. Effects of depressive symptoms on clinical outcomes, inflammatory markers and quality of life after a significant weight loss in a bariatric surgery sample. Nutr Hosp. 2017;34:81-7. 